TẠP CHÍ KHOA HỌC ĐẠI HỌC TÂN TRÀO

ISSN: $2354-1431$

http://tckh.daihoctantrao.edu.vn/

\title{
Biên soạn từ điển đối dịch trước nguy cơ mai một các ngôn ngữ ở Việt Nam
}

\author{
Tạ Văn Thông ${ }^{a *}$ \\ ${ }^{a}$ Viện Tù điển học và Bách khoa thu Việt Nam \\ *Email: tavanthong1955@gmail.com
}

Thông tin bài viết

Ngày nhận bài:

20/7/2018

Ngày duyệt đăng:

$10 / 12 / 2018$

\section{Tù khóa:}

Tù điển; tù vựng học; ngôn ngũ dân tộc thiểu số; ngôn ngũ có nguy co mai một

\section{Tóm tắt}

Nhiều dân tộc thiểu số ở Việt Nam hiện nay đang đứng trước nguy cơ mai một ngôn ngữ đồng thời thất lạc các hình thái văn hóa được lưu giữ và phát triển bằng tiếng mẹ đẻ của mình. Biên soạn các từ điển được xem là một trong những biện pháp giúp ngôn ngữ trên dừng lại trước nguy cơ này.

Từ điển đối dịch là loại từ điển giải thích những đơn vị từ ngữ (đầu mục) của một ngôn ngữ, bằng ngôn ngữ thứ hai, nghĩa là bằng cách dịch cái này ra cái kia.

Bài viết này có nhiệm vụ: Từ lí thuyết và thực tế biên soạn từ điển đối dịch (TĐĐD, còn gọi là "từ điển đối chiếu"; hoặc "từ điển hai thứ tiếng", "từ điển song ngữ" - căn cứ vào dạng thường gặp của loại từ điển này), xác định những yêu cầu đặt ra và phương hướng giải quyết trong việc biên soạn các từ điển Việt dân tộc thiểu số và dân tộc thiểu số - Việt.

Đó là: Các loại từ điển đối dịch cần có ở Việt Nam; chữ viết; chọn tiếng địa phương; xác lập bảng đầu mục: dung lượng, những loại đơn vị ngôn ngữ, nguồn thu thập từ ngữ. Ngoài ra: đối dịch trong từ điển như thế nào.
1. Nhiều dân tộc thiểu số (DTTS) ở Việt Nam đang đứng trước nguy cơ mai một ngôn ngữ tộc người đồng thời thất lạc các hình thái văn hóa được lưu giữ và phát triển bằng tiếng mẹ đẻ của mình. Nguy cơ đó, trong hoàn cảnh thực tế hiện nay, ngày càng rõ rệt.

Nhân tố quan trọng nhất đem lại sức sống cho các ngôn ngữ là chúng được truyền dạy và có vai trò (được sử dụng) trong đời sống xã hội. Đây là điều kiện tồn tại, giúp ngôn ngữ thoát ra khỏi tình trạng "suy yếu" hoặc "nguy cấp", trở thành "khỏe mạnh".

Các biện pháp: xác định phương hướng kế hoạch hóa và xây dựng chính sách ngôn ngữ; nghiên cứu cơ bản về cấu trúc, tình hình xã hội ngôn ngữ học; cải tiến và xây dựng các hệ thống chữ viết; biên soạn các sách công cụ (sách giáo khoa, sách ngữ pháp, từ điển...); sưu tập các văn bản (vốn văn nghệ truyền thống; sáng tác mới...) và ghi bằng các ngôn ngữ có nguy cơ mai một; dạy và học các ngôn ngữ có nguy cơ tiêu vong và sử dụng chúng trên các phương tiện thông tin đại chúng; thu thập, lưu trữ để xây dựng ngân hàng dữ liệu; giúp cho người bản ngữ có ý thức bảo tồn, phát triển tiếng mẹ đẻ... Biên soạn các từ điển được xem là một trong những biện pháp giúp ngôn ngữ các DTTS dừng lại trước nguy cơ mai một, thậm chí tiêu vong.

Bài viết này có nhiệm vụ: Từ lí thuyết và thực tế biên soạn từ điển đối dịch (TĐĐD, còn gọi là "từ điển đối chiếu"; hoặc "từ điển hai thứ tiếng", "từ điển song ngữ" - căn cứ vào dạng thường gặp của loại từ điển này), xác định những yêu cầu đặt ra và phương hướng giải quyết trong việc biên soạn các từ điển Việt - dân tộc thiểu số (DTTS) và DTTS - Việt.

Từ điển đối dịch (translation dictionary) còn gọi là "từ điển đối chiếu"; hoặc "từ điển hai thứ tiếng", "từ điển song ngữ" - căn cứ vào dạng thường gặp của loại từ điển này. Đây là loại từ điển giải thích những đơn vị từ ngữ (được quy ước là đầu mục) của một ngôn ngữ, 
bằng một hoặc một số từ tương đương trong ngôn ngữ thứ hai, nghĩa là bằng cách dịch cái này ra cái kia. Từ điển đối dịch có nhiều loại, trong đó dạng điển hình của từ điển này là từ điển song ngữ.

\section{Biên soạn từ điển đối dịch Việt - DTTS và DTTS - Việt ở Việt Nam}

Quá trình biên soạn các từ điển đối dịch trong đó có một ngôn ngữ thuộc DTTS ở Việt Nam có lịch sử lâu dài nhưng chủ yếu gần đây. Có khoảng trên 160 cuốn thuộc loại này.

Trong thời kì thuộc Pháp, các nhà khoa học thuộc các tổ chức khác nhau và các linh mục đã tiến hành những hoạt động nghiên cứu ngôn ngữ học, không chỉ chú ý đến tiếng Việt mà còn chú trọng đến ngôn ngữ các DTTS.

Sau đây là một số cuốn từ điển đối dịch được biên soạn thời Pháp (sắp xếp theo thứ tự thời gian):

- Aymonier R., Cabaton A. (1906), Dictionnaire Cam - Francais, Imprimerie Nationale, Paris.

- Savina F.M. (1916), Dictionnaire miao-tseufrancais, Bulletin de l'Ecole Francaise d'ExtremeOrient 16 (2).

- Savina F.M. (1920), Abecedaire Meo - Francais, Hanoi: Imprimerie d'Extreme Orient.

- Savina F.M. (1920), Lexique Francais - meo, Hanoi: l'Ecole Francaise d' Extreme Orient.

- Savina F. M. (1924), Dictionnaire étymologique Français - Nung - Chinois, Hongkong.

- Savina F.M. (1927), Dictionnaire francais-man precede d'une note sur les man kim-di-mun et leur langue, Bulletin de l'Ecole Francaise d'Extreme-Orient.

- Gerber Théophile (1937), Lexique Franco - Stieng, Saigon Imprimerie Théêtre.

- Dournes J. (1953), Dictionnaire Sre (Koho) Francairs, Dalat.

- Gilbert Bochet et Jacques Dournes (1953), Dictionnaire Francairs - Koho - Roglai - Viêtnamien, France - Asie, Saigon...

Trong thời kì trước năm 1975, ở miền Nam có sự hoạt động của các trung tâm và tổ chức nước ngoài nghiên cứu về Việt Nam, trong đó chủ yếu là Viện Ngữ học Mùa hè (SIL - Summer Institute of Linguistics) với mục đích là "nghiên cứu các ngôn ngữ trong văn hóa các dân tộc, nhằm mục đích giáo dục song ngữ và truyền giáo". Ở miền Bắc có các cơ quan nghiên cứu và các trường đại học nghiên cứu ngôn ngữ các dân tộc thiểu số, trong đó chủ yếu là Ủy ban Khoa học xã hộ $i$ (nay là Viện Hàn lâm Khoa học xã hội Việt Nam) và Trường Đại học Tổng hợp Hà Nội. Tiếp theo là thời kì đất nước thống nhất và công việc nghiên cứu biên soạn chủ yếu là của các tác giả Việt Nam.

Sau đây là một số cuốn từ điển đối dịch rất đa dạng về loại, được biên soạn vào thời kì này:

- Blood David L. (1961), Cham - Vietnamese English, SIL / UND.

- Louison Benjamin R.P. (1964), Dictionnaire Rhadé - Francairs, Dalat.

- Kenneth D. Smith (1967), Sedang Vocabulary (Sedang - Việt - English), SIL, Bộ Giáo dục Saigon.

- Gregerson Kenneth J., Marilyn Gregerson, Andre Ir (1969), A Rengao Dictionary, SIL, Bộ Giáo dục Saigon.

- Nguyễn Văn Chỉnh (1971), Tù điển Mèo - Việt, Nxb Khoa học xã hội, $H$.

- Moussay G. (1971), Dictionnaire Cam Vietnamien - Francairs, Trung tâm Văn hóa Chăm, Phan Rang.

- Hoàng Văn Ma, Lục Văn Pảo, Hoàng Chí (1974), Tù điển Tày-Nùng - Việt, Nxb Khoa học xã hội, $\mathrm{H}$.

- Vy Thị Bé, Nancy F. Wilson, Janice Saul (1974), Tù điển Nùng - Việt - Anh, SIL.

- Awơi-hathe, Ayiong... (1977), Suraq vungã sanãp Radlai - Ngũ vụng Rogglai. Northern Roglai Vocabulary, SIL, Manila.

- Rơmah Del (1977), Tù điển Việt - Gia rai, Nxb Khoa học xã hội, H.

- Hoàng Văn Ma, Lục Văn Pảo (1984), Tù điển Việt - Tày-Nùng, Nxb Khoa học xã hội, H.

- Nguyễn Phú Phong, Trần Trí Dõi, M. Ferlus (1988), Lexique Vietnamien - Ruc - Francais, Universite de Paris VII.

- Hoàng Trần Nghịch, Tòng Kim Ân (1990), Tù diển Thái - Việt, Nxb Khoa học xã hội, H.

- Lục Văn Pảo (1991), Thành ngũ Tày - Nùng (giải thich bằng tiếng Việt), Nxb Văn hóa dân tộc, $\mathrm{H}$.

- Costelo N.A. (1991), Katu Dictionary (Katu Vietnamese - English), SIL, Manila.

- Hoàng Văn Hành, Phan Văn Phức, Đoàn Văn Phúc, (1994), Hdruôm hră mblang Yuăn - Êđê (Tù điển Việt - Êđê), Sở Giáo dục Đắk Lắk. 
- Bùi Khánh Thế (chủ biên), Đinh Lê Thư... (1995), Tù̀ điển Chăm - Việt, Nxb Giáo dục, $\mathrm{H}$.

- Bùi Khánh Thế (chủ biên), Phú Trạm, Quảng Đại Cẩn (1996), Tù̀ điển Việt - Chăm, Nxb Khoa học xã hội, $\mathrm{H}$.

- Triều Ân, Hoàng Quyết (1996), Tù điển thành ngũu - tục ngũu dân tộc Tày, Nxb Văn hóa dân tộc, H.

- Nguyễn Văn Chỉnh (chủ biên), Cư Hòa Vần, Nguyễn Trọng Báu (1996), Tù điển Việt - Mông (Việt Hmôngz), Nxb Giáo dục, $\mathrm{H}$.

- Kenneth D. Smith (2000), Sedang Dictionary with English, Vietnamese, and French Glossaries (Tù diển Xo-đăng - Anh - Việt - Pháp), A Journal of Southeast Asian Languages.

- Cư Hòa Vần, Nguyễn Văn Chỉnh... (2001), Tù điển Mông - Việt, Nxb Giáo dục, H.

- Đinh Lê Thư, Y Tông Drang... (2006), Tù diển Việt - Mnông Lâm, Nxb ĐHQG Tp HCM.

- Nguyễn Hữu Hoành, Tạ Văn Thông, Nguyễn Văn Lợi (2007), Tù điển Co tu - Việt, Việt - Co tu, Quảng Nam.

- Lê Đông, Tạ Văn Thông (2008), Tù điển Việt - Xo đăng, Nxb Văn hóa Thông tin, H.

- Tạ Văn Thông (chủ biên - 2015), Tù điển Êđê Việt, Nxb Giáo dục Việt Nam, H.

- Mông Ký Slay, Vương Toàn, Phạm Ngọc Thưởng, Nông Hồng Thăng (2016), Tù điển Nùng Việt, Nxb Đại học Thái Nguyên...

Thực tế hiện nay: Bên cạnh những nghiên cứu cơ bản về ngôn ngữ các DTTS, việc biên soạn các từ điển đã trở thành nhu cầu đối với nhiều ngành, nhiều địa phương ở vùng DTTS. Loại công trình tra cứu thường gặp ở Việt Nam: tù̀ diển Việt - DTTSvà DTTS - Việt. Tuy số từ điển được biên soạn ngày càng nhiều và càng đa dạng, nhưng do các tác giả có những mục đích, quan niệm và kĩ thuật khác nhau, và nói chung chưa được tổ chức, nên vẫn chỉ đáp ứng được phần nào nhu cầu thực tế.

\section{Một số vấn đề đặt ra trong biên soạn từ điển đối dịch Việt - DTTS và DTTS - Việt ở Việt Nam}

\subsection{Các loại tù điển đối dịch cần có ở Việt Nam}

Các loại từ điển đối dịch đã được biên soạn ở Việt Nam khá nhiều và không ít kiểu loại. Đó là:

- Xét về tiêu chí "số lượng" các ngôn ngữ đưa vào từ điển, các từ điển đối dịch này chủ yếu là song ngữ, nhưng cũng không ít liên ngữ (thường là $b a$, it gặp hơn là bốn). Có thể có cả tiếng nước ngoài. Ví dụ loại thứ hai: Shintani Tadahiko L.A. (1981), Boh blu Êđê Yuăn - Zapônê (Tù điển Êđê - Việt - Nhật, 1981); Vương Hữu Lễ (1997), Tù diển Bru - Việt - Anh (Saráq parnai Brũ - Yuan - Anh); Kenneth D. Smith (2000), Sedang Dictionary with English, Vietnamese, and French Glossaries (Tù điển Xo-đăng - Anh - Việt Pháp)....

- Xét về tiêu chí "hướng" trong một cuốn từ điển, các từ điển đối dịch này chủ yếu là đơn hướng, ví dụ: Tù điển Tày - Việt, Tù̀ điển Bru - Việt - Anh..., nhưng cũng có thể đa hướng: Tù điển Cơtu - Việt, Việt Cotu...

- Xét về tiêu chí "cho ai", phần lớn từ điển đối dịch đã được biên soạn ở Việt Nam hướng đồng thời tới hai loại đối tượng sử dụng, là những người biết DTTS và tiếng Việt. Trong một số từ điển đối dịch, đối tượng này là cả những người biết ngoại ngữ hoặc người nước ngoài. Có thể gặp một số cuốn từ điển đối dịch hướng chủ yếu tới một đối tượng.

- Xét về tiêu chí “để làm gì", thường các cuốn từ điển đối dịch được biên soạn với nhiều mục đích thực tế, nói chung thường là giúp người sử dụng hiểu các văn bản hay miêu tả ngôn ngữ gốc, hoặc giúp cho việc hiểu và "viết ra được" những văn bản bằng ngôn ngữ đích. Tất nhiên, mỗi loại từ điển đối dịch thường có tính đặc thù và số lượng các ngôn ngữ có thể tỉ lệ thuận với số mục đích trong một cuốn từ điển.

- Xét theo các tiêu chí "hướng", tính chất từ ngữ, khuôn khổ..., cũng có thể thấy ở Việt Nam các kiểu loại từ điển đối dịch không ít. Tuy nhiên, có thể nhận xét chung rằng: Loại từ điển đối dịch đơn hướng (" $L 1$ ” “ $L 2$ ”) thường gặp hơn đa hướng $L 1$ ” - “ $L 2$ ”; “ $L 2$ ” “ $L 1$ ”)); Loại từ điển đối dịch thông thường chiếm đa số (còn loại tù điển đối dịch gồm các thuật ngũ thì it gặp); Loại từ điển đối dịch cỡ "nhỏ" (và rất nhỏ) thường gặp hơn cỡ "trung", còn cỡ "lớn" thì hầu như không có.

Có thể thấy các từ điển đối dịch đã được biên soạn ở Việt Nam rất đa dạng. Điều này có thể do điều kiện kinh tế hay nhân lực khác nhau, hoặc đó là bước mở đầu hay sau đó, hoặc sự nghèo nàn hay giàu có từ vựng của các ngôn ngữ, hoặc sự "thiếu sót" này khác của các tác giả... Tuy nhiên, có thể sự phong phú đa dạng (bao gồm cả sụ đơn giản hay chi tiết, nhỏ hay trung bình hay lớn...) ấy chỉ nhằm đáp ứng những yêu cầu khác nhau trong đời sống, mỗi loại có giá trị riêng. Những yêu cầu ấy chi phối cấu trúc vĩ mô và vi mô của các cuốn từ điển đối dịch, theo hướng linh hoạt 
hóa. Trên thực tế, quan niệm không đầy đủ về từ điển đối dịch và đặc biệt định kiến rằng những cuốn từ điển đối dịch nhất thiết phải theo một kiểu mẫu "chân chính", vừa không đúng về mặt lí luận vừa hạn chế sự góp mặt của các từ điển đối dịch, nhiều khi khiến người biên soạn phải bối rối do điều kiện không cho phép. Cũng trên thực tế, các từ điển đối dịch đã được biên soạn ở Việt Nam chỉ mới đáp ứng được một phần những yêu cầu đủ loại, ở những mức độ rất khác nhau của đời sống. Cần có nhiều hơn những cuốn từ điển như vậy, và càng đa dạng càng tốt. Chẳng hạn, ngoài các cuốn như đã nói ở trên, đó có thể là các từ điển về mặt nào đó trong văn hóa cổ truyền; từ điển từ láy; từ điển dành cho học sinh; từ điển theo một trường từ vựng - ngữ nghĩa nào đó; từ điển phương ngữ; từ điển chữ Nôm; từ điển về từ ngữ trong tác phẩm văn nghệ dân gian..., với các kích cỡ và cách thức đối dịch, song ngữ hay liên ngữ khác nhau. Trong sự đa dạng này, không nên "bỏ quên" các ngôn ngữ DTTSđang đứng trước nguy cơ tiêu vong như Pà Thẻn, Pu Péo, La Ha, Bố Y, Cơ Lao, Co, Rơ Măm... Về điều này, xin trích dẫn ý kiến của L.Zgusta: "Có lẽ mặt quan trọng nhất của loại hình từ điển song ngữ là nằm trong ý định của nhà từ điển học" [19, tr 372].

\subsection{Chũ viết trong tù̀ điển đối dịch}

Mặc dù có không ít nhược điểm nhưng chữ Quốc ngữ (chữ ghi tiếng Việt) về cơ bản không gây ra những khó khăn lớn cho người biên soạn. Tuy nhiên, khó khăn từ cách ghi bằng Quốc ngữ không phải là không có trong một cuốn từ điển đối dịch, đặc biệt là loại từ điển đối dịch DTTS - Việt. Chẳng hạn, đó là khi cần phiên chuyển các từ ngữ (với những đặc tính ngữ âm tiếng Việt không có) từ tiếng từ điển đối dịch sang tiếng Việt, hoặc cách ghi các tên riêng... Cũng tương tự, khi cần phiên chuyển các từ ngữ từ tiếng Việt sang tiếng từ điển đối dịch. Trong các trường hợp này, người ta đành chấp nhận cách ghi "na ná", viết thế nhưng đọc không hoàn toàn như thế.

Tất nhiên, đối với những từ điển đối dịch chưa có chữ viết riêng (ở Việt Nam, có tới nửa số từ điển đối dịch chưa có chữ), thì không thể khác là phải chế tác một hệ thống chữ trước khi nghĩ đến việc biên soạn bất kì cuốn từ điển nào có liên quan đến ngôn ngữ của họ.

Một thực tế khác: Nhiều dân tộc ở nước ta đã có chữ viết. Có hai loại chữ là "cổ truyền" (chữ dạng vuông gốc Hán; chữ dạng Sanscrit gốc Ấn Độ...) và chữ "mới” (dạng latin). Một số dân tộc chỉ có một bộ chữ viết, một số dân tộc lại có tới hai, ba, và thậm chí còn nhiều hơn do có nhiều biến thể địa phương hoặc cá nhân hay một nhóm xã hội nào đó. Một số dân tộc vừa có chữ "cổ truyền" vừa có chữ "mới".

Trong trường hợp như vậy, căn cứ vào mục đích cụ thể của từ điển đối dịch đang biên soạn, có thể cân nhắc những cách giải quyết như sau:

- Có hai (hoặc trên hai) cuốn từ điển, một ghi bằng chữ này và một (hoặc trên một) ghi bằng chữ kia. Hoặc: Trong một cuốn từ điển có cả cách ghi bằng chữ này cả bằng chữ kia. Hoặc: Trong một cuốn từ điển ghi chủ yếu bằng chữ này có ghi chú thêm bằng chữ kia. Cách này rất cần thiết đối với những dân tộc vừa có chữ "cổ truyền" vừa có chữ "mới".

- Uu tiên bộ chữ nào có triển vọng hơn đối với việc truyền bá (giáo dục) và sử dụng (trong đời sống hàng ngày; trong các hoạt động văn hóa truyền thông...). Chú ý đến bộ chữ có tính pháp lí (có sự phê chuẩn của cơ quan có thẩm quyền), vì đây cũng là điều kiện để có triển vọng. Liên quan đến điều này còn là: Bộ chữ nào hiện đang có nhiều người biết hơn, đang được dùng trong nhiều ấn phẩm hơn, dễ học dễ nhớ dễ viết hơn. Triển vọng này còn có thể được thể hiện ở chỗ: Những người bản ngữ đã biết cả hai bộ chữ này thì thích và quen sử dụng chữ nào hơn.

- Uu tiên bộ chữ nào gần với chữ Quốc ngữ hơn (về tự dạng; về nguyên tắc và mối quan hệ giữa kí hiệu với nội dung biểu đạt). Sở dĩ như vậy, là vì chữ đó với Quốc ngữ cùng xuất hiện trong một văn bản, đồng thời người đọc vừa là người thuộc từ điển đối dịch vừa là người Kinh, hoặc là người dân tộc khác nữa nhưng thường biết tiếng Việt. Các hệ thống chữ càng gần nhau thì càng thuận lợi cho độc giả khi tra cứu và đọc hoặc ghi lại, thậm chí học tập qua từ điển.

\subsection{Tiếng địa phương trong tù điển đối dịch}

Thường thì sự khác biệt giữa những tiếng địa phương của tiếng Việt không gây ra những khó khăn lớn cho người biên soạn: Phần tiếng Việt thường là các từ ngữ của tiếng Việt phổ thông. Tuy nhiên, khó khăn nảy sinh khi gặp các biến thể địa phương ngôn ngữ các DTTS: các từ ngũ̃ riêng biệt của từng vùng hay nhóm xã hội cần đưa vào từ điển.

Hầu hết các ngôn ngữ DTTS có nhiều tiếng địa phương. Một vài trường hợp sự khác biệt giữa các tiếng địa phương tới mức người nói hiểu được nhau có phần khó khăn. Tuy nhiên, cũng như trong tiếng Việt, sự khác biệt giữa những tiếng địa phương chủ yếu là ở "giọng nói” (ngũ âm), thường có quy luật đối ứng chặt chẽ, đều đặn. Những khác biệt về từ vựng - ngữ nghĩa 
thường ít và không có tính đối ứng. Ít gặp hơn nữa là những khác biệt về ngữ pháp... Cũng như đối với các hệ thống chữ viết, nhiều khi việc lựa chọn tiếng địa phương nào để thể hiện trong từ điển nhiều khi khó thống nhất, và cuốn từ điển có được độc giả đón nhận (tức là có ích lợi) hay không cũng có thể liên quan đến điều này.

Trong trường hợp như vậy, căn cứ vào mục đích cụ thể của từ điển đối dịch đang biên soạn, có thể cân nhắc những cách giải quyết như sau:

- Có hai (hoặc trên hai) cuốn từ điển, một ghi nhận biến thể địa phương này và một (hoặc trên một) ghi nhận biến thể địa phương kia. Hoặc: Trong một cuốn từ điển có cả sự ghi nhận biến thể địa phương này và biến thể địa phương kia. Hoặc: Trong một cuốn từ điển chủ yếu ghi nhận biến thể địa phương này và có ghi chú thêm biến thể địa phương kia. Cần lưu ý: Sự khác biệt giữa các tiếng địa phương về "giọng nói” (ngữ âm) có quy luật đối ứng chặt chẽ và không cần thể hiện ở các mục từ, mà chỉ cần chỉ ra tính quy tắc của chúng (thường ở phần đầu sách). Sự ghi nhận ở đây chủ yếu về mặt từ vựng - ngữ nghĩa. Khi có đồng thời các từ ngữ vốn thuộc các địa phương khác nhau, thì nên sắp xếp theo thứ tự ưu tiên (đứng trước) là các từ ngữ có tính phổ biến cao.

Một vấn đề phát sinh: chữ của một từ điển đối dịch có thể không ghi được "giọng" của nhiều địa phương. Lấy ví dụ cho điều này là chữ Tày (Tày - Nùng). Trong cuốn Tù điển Tày - Việt (2011), nhận thấy chữ không có dấu ghi một thanh có âm vực trầm, trường độ dài rất phổ biến ở các vùng Tày đông bắc Lạng Sơn, nam Cao Bằng, Bắc Cạn, Thái Nguyên..., nên các tác giả đã dùng thêm dấu "lửng" ( là một sáng tạo có căn cứ, tuy có phần tùy tiện.

- Uuu tiên tiếng địa phương nào có triển vọng hơn đối với việc truyền bá (giáo dục) và sử dụng (trong đời sống hàng ngày; trong văn hóa truyền thông...). Liên quan đến điều này là tiếng địa phương được người bản ngữ xem là "có uy tín", "dễ nghe dễ hiểu” và thậm chí là “chuẩn”. Đó thường là tiếng địa phương được nhiều người biết đến, do là tiếng ở một vùng có ưu thế về chính trị, kinh tế và văn hóa, hoặc ở vị trí trung tâm giữa các vùng khác, hoặc của nhóm địa phương có số dân đông, hoặc có khi vì đó là tiếng của địa phương có di tích lịch sử hay thắng cảnh, có anh hùng hay nhà văn hóa...; rất thường là tiếng địa phương đã được chọn để xây dựng chữ viết, và/ hoặc đã được sử dụng trên các phương tiện thông tin đại chúng...
Cách thứ hai này thường được dùng ở Việt Nam.

(Tham khảo: Trong hầu hết các cuốn từ điển ở Việt Nam nói chung (trừ từ điển phương ngữ) và từ điển đối dịch nói riêng, tiếng địa phương việc lựa chọn để thể hiện thường là (hoặc chủ yếu dựa vào) tiếng ở trung tâm chính trị, kinh tế và văn hóa. Một ví dụ cần kể đến trước tiên, đó là tiếng Việt. Ngoài ra, trong Tù điển tiếng Việt (Viện Ngôn ngũ họ - 2006), bên cạnh các từ ngữ "phổ thông”, cũng ghi nhận cả những từ ngữ địa phương).

\subsection{Xác lập bảng đầu mục trong tù̀ điển}

\section{1/ Dung lựng các đầu mục phải là bao nhiêu?}

Nói đến đầu mục tức là nói đến các từ ngữ được tuyển chọn (được coi là "xương sống" của cuốn từ điển) thuộc ngôn ngữ gốc.

Căn cứ vào khuôn khổ của từ điển đối dịch, có thể phân biệt các loại khác nhau: cỡ nhỏ, cỡ vừa và cỡ lớn. Tiêu chí để phân biệt các loại như vậy thực ra rất đại khái. Từ điển "cỡ nhỏ" có số lượng các mục rất ít (chỉ nên có trên dưới 10.000 mục) và thường không có các ví dụ (còn gọi là "ngữ cảnh"). "Cỡ lớn” khoảng 70.000 - 80.000 mục trở lên. Ở khoảng giữa là "cỡ vừa".

Trên thực tế, người ta thường trước hết biên soạn một cuốn nhỏ, sau đó trên cơ sở đó bổ sung thêm, thêm nữa, và để phân biệt ba cuốn này phải gọi chúng là: cỡ nhỏ, cỡ vừa và cỡ lớn.

Có tác giả phân biệt thành từ điển cỡ nhỏ, từ điển bỏ túi, từ điển cỡ trung bình, từ điển cỡ lớn... Tất nhiên, các tiêu chí "nhỏ, vừa, lớn, bỏ túi..." này chỉ là tương đối, trong mối tương quan với nhau ở một phạm vi nhất định, hoặc phụ thuộc vào quan điểm của người biên soạn. Ngoài những điều nói trên, "cỡ" của một cuốn từ điển đối dịch còn phụ thuộc vào những yêu cầu khác nhau của người sử dụng, đồng thời quan trọng không kém là trong các ngôn ngữ trong từ điển có vốn từ ở mức nào (có những ngôn ngữ rất phát triển và có những ngôn ngữ rất nghèo nàn về vốn từ). Trong trường hợp này, đặt một cuốn từ điển này bên cạnh cuốn kia, với sự phàn nàn đáng lẽ "cỡ” của chúng phải đồng nhất, là một sự so sánh bất công và yêu cầu không chính đáng.

Ladislav Zgusta đã đưa ra một nhận xét đáng lưu ý, rằng nói đúng ra là không thể đưa ra một quan niệm chính xác thế nào là "cỡ” của từ điển vì đây rốt cuộc chỉ là sự ước lượng đại khái, và có lẽ dùng những thuật ngữ chỉ mức độ hoàn hảo hay tính phong phú của một cuốn từ điển sẽ tốt hơn và đỡ phiền phức hơn là "cỡ". Ông cũng nói rằng: "Sẽ là một sai lầm nếu nghĩ rằng một 
cuốn từ điển hàn lâm cỡ lớn sẽ đưa vào “đủ mọi thứ" và các từ điển biến thể nhỏ hơn chỉ là sự rút gọn về lượng trên cơ sở cuốn lớn kia” [19, tr 305].

Tóm lại: Dung lượng các đầu mục (và nói chung cả cấu trúc vĩ mô) bao nhiêu là tùy thuộc vào loại, mục đích, yêu cầu, đối tượng của các cuốn từ điển, vào quan điểm của người biên soạn.

2/ Danh sách đầu mục gồm nhũng loại đơn vị ngôn ngũu nào?

Câu trả lời: Thường là từ (từ đơn; ghép; láy; phái sinh), nhưng cũng có thể lớn hơn từ (cụm từ), được tuyển chọn theo mục đích, yêu cầu, tính chất của cuốn từ điển, được sắp xếp theo thứ tự chữ cái.

Trong hầu hết các ngôn ngữ ở Việt Nam hiện nay, việc xác định khái niệm "từ" và ranh giới từ là vô cùng khó khăn. Bởi vậy, cần có sự tìm hiểu kĩ các đặc điểm từ vựng - ngữ pháp - ngũ̃ nghĩa của ngôn ngữ đối tượng, đồng thời cân nhắc đến tính tiện dung và lợi ích của độc giả. Khi biên soạn cần có một quy định (có thể võ đoán) về việc đưa loại từ ngữ này và không phải loại kia, nếu không số lượng các đơn vị ngôn ngữ, đặc biệt các cụm từ) này sẽ rất lớn do có thể thu thập "nhầm" cả những cụm từ tự do.

Các chữ viết tắt, từ tắt (đại diện cho từ hoặc cụm từ); thành ngữ; cụm từ có tính thành ngữ đều có thể được đưa vào từ điển.

Về các lớp từ: Trong một cuốn từ điển đối dịch thông thường, cần ưu tiên thu thập trước hết cho bảng đầu mục là các từ ngữ thuần của ngôn ngữ gốc.

Rất nên cân nhắc liều lượng khi đưa vào bảng đầu mục các từ ngữ mang tính địa phương (không phổ thông); các từ ngữ vay mượn và thuật ngữ. Chúng cần được đưa vào những cuốn từ điển chuyên biệt. Các tên riêng không nên đưa vào từ điển loại này: chúng thuộc loại công trình gọi là "bách khoa thư". Tóm lại, điều đó có liên quan đến tính chất của loại công trình đang nói: gồm tất cả các từ ngữ của ngôn ngữ hay chỉ một lớp loại nhất định.

Cụ thể:

Đối với công trình ghi nhận tất cả các từ ngữ trong ngôn ngữ DTTS, thì bảng đầu mục gồm:

- Các từ ngữ thường dùng trong đời sống hàng ngày, trong các hình thức văn nói và văn viết.

- Các từ ngữ thuộc phương ngữ được dùng tương đối phổ biến trong các loại văn bản thời gian gần đây.

- Các từ ngữ cổ được dùng tương đối phổ biến trong các loại văn bản thời gian gần đây.
- Các từ ngữ mới được sáng tạo được dùng tương đối phổ biến trong các loại văn bản thời gian gần đây.

- Các thuật ngữ khoa học kĩ thuật được dùng tương đối phổ biến trong thời gian gần đây.

- Các chữ viết tắt được dùng tương đối phổ biến trong các loại văn bản thời gian gần đây...

Nguồn thu thập từ ngữ là đâu?

Khi muốn xây dựng một cuốn từ điển song ngữ $\mathrm{A}$ $\mathrm{B}$ :

Cách thư nhất: đơn giản nhất là dựa vào một một cuốn từ điển về ngôn ngữ $\mathrm{A}$ cùng dung lượng và sử dụng cấu trúc vĩ mô của nó".

Cách thứ hai: sách báo, trong đó chú trọng đến các ấn phẩm trong thời gian gần đây.

Cách thứ ba: lời nói (khẩu ngữ) hàng ngày.

Việc xác lập bảng đầu mục trong cấu trúc vĩ mô (gồm cả việc xác định mối quan hệ giữa các yếu tố và nghệ thuật sắp đặt) trong biên soạn các từ điển Việt DTTSvà DTTS- Việt là rất quan trọng, vì nó đã tạo dựng nên "bộ xương" của công trình. Tất nhiên, cần có hàng loạt công việc khác nữa để tạo nên hình hài cho tác phẩm: chữ viết; phương ngữ; cách giải thích bổ sung và xử lí khi không có từ ngữ tương đương khi đối dịch; từ loại; từ đa nghĩa và đồng âm; ví dụ...

\subsection{Về việc đối dịch trong tù điển}

Sự tương đương giữa các từ ngữ của các ngôn ngữ có thể là hoàn toàn nhưng cũng có thể chỉ là một phần, xét về cả nghĩa lẫn loại đơn vị thể hiện. Thậm chí, nhiều khi không thể tìm thấy sự tương đương. Điều đó có lí do, liên quan đến tính đặc thù về hình thái, ngữ pháp, từ vựng - ngữ nghĩa của từng ngôn ngữ, đồng thời do hoàn cảnh sống nên có những hiện tượng và sự vật chỉ thấy trong cộng đồng này mà không thấy trong cộng đồng kia, hoặc cùng một hiện tượng sự vật nhưng được các cộng đồng khác nhau tri nhận không như nhau.

Một số ví dụ: Từ kin tiếng Tày tương ứng với "ăn" (kin khẩu: ăn cơm), đồng thời với "uống" (kin lẩu; uống rượu), với "hút" (kin lảo keo: hút thuốc lào); Từ uống (Việt) tương ứng với hai từ trong tiếng Cơ ho: HÙC. hùc dà: uống nước; NHÔ. nhô tornòm: uống rượu; Từ nheq $(\mathrm{Bru})$ vừa có nghĩa là "hết" vừa nghĩa là "tất cả”, nsễng vừa là "mỡ" vừa là "béo"; Từ $e a(\hat{E}$ Đê, Gia Rai) hay dak, dà, năm/nậm (Mnông, Cơ Ho, Tày, Thái...) tương ứng với một số từ trong tiếng Việt: nước, sông, suối... Hoặc trong nhiều ngôn ngữ DTTS ở Việt Nam có nhiều loại “gùi”, "chiêng”, "tre”, "kiến”, "châu chấu”, "bẫy”... với những tên gọi riêng, bởi vậy trong 
các từ điển đối dịch DTTS - Việt hoặc DTTS - ngoại ngữ, thường thấy có ghi bên phải từ đầu mục là: "một loại gùi”, "một loại tre", "một loại kiến"... Đối với những trường hợp này, sẽ tốt hơn nếu dùng lối miêu tả.

Hoặc: Trong tiếng Cơ Ho, không có các khái niệm “đông, tây..." như quan niệm của người Việt, nên trong Từ điển Việt - Kơho (1983) đã ghi:

ĐÔNG Đah mát tơngai lík (nghĩa là: "hướng mặt trời ra")

TÂY Đah mát tơngai mút (nghĩa là: "hướng mặt trời vào")...

Hoặc những khác biệt về nghĩa trong các cặp từ tiếng Ta Ôi sau rất khó tìm sự tương đương một đối một với tiếng Việt:

tik: trên kia; tik: trên kia (gần hơn tik)

têh: trên kia ( xa hơn tik và tik); tếh: trên kia (gần hơn têh)

Hoặc những khác biệt về nghĩa trong các cặp từ tiếng Ta Ôi sau có kèm sự bực dọc chê bai:

jeeu (lười); jeeuq (lười quá đáng (!))

lơau (thưa); loauq (thưa quá đáng (!))...

Trong trường hợp khó khăn khi tìm sự tương đương, căn cứ vào mục đích chung của từ điển đối dịch, nên cân nhắc những cách giải quyết như sau:

- Dùng cách giải thích. Ví dụ trong Tù điển Thái Việt (1991):

MÁK KHÉN thứ hạt cay trong rừng làm gia vị.

TẢNGG CẢU búi tóc ngược lên đỉnh đầu.

Đây là cách rất phổ biến trong biên soạn từ điển đối dịch. Nó đòi hỏi cao đối với các soạn giả: không phải chỉ cần hiểu rõ cái được biểu đạt qua các từ ngữ của ngôn ngữ gốc mà còn phải biết cách tường giải bằng ngôn ngữ đích. Lưu ý: Soạn giả cần tránh giải thích cái cần biết bằng cái chưa biết.

Việc cung cấp nhiều từ ngữ đồng nghĩa trong ngôn ngữ đích rất quan trọng: không chỉ giúp cho việc hiểu rõ hơn từ ngữ của ngôn ngữ gốc, do các từ ngữ đồng nghĩa này bổ sung các nét nghĩa cho nhau trong đó có những sắc thái tu từ, mà còn giúp việc dịch thuật có nhiều khả năng lựa chọn. Ví dụ trong Từ điển Việt Koho (1983):

KÉO Kơltung, tì, huài, tơrhuài. Kéo cho cây đổ: Koltung chi làng gơplừ. Ho kéo nhau: Vol khai tam tơrhuài. Trâu kéo cày: Rơpu huài ngal.
Một cách khác có thể tham khảo: người biên soạn dùng cách ghi chú (để trong ngoặc đơn) để giới hạn phạm vi sử dụng và cách dùng thích hợp đối với từ ngữ của ngôn ngữ đích. Ví dụ trong Tù điển Thái - Việt (1991):

MÃN XẢY chửa (cá, ếch, nhái). Pa mãn xáy: cá chửa.

DÃO 1. dài (kích thước). Pỏng dão: gióng dài. Tăng dão: đường dài; đường trường. 2. rộng (tấm lòng)...

Hỗ trợ cho việc giải thích nói trên còn có các ví dụ (ngữ cảnh). Trong biên soạn từ điển, ví dụ thường được xem là cái tạo nên hình hài của các mục từ, đồng thời có vai trò rất quan trọng trong việc làm rõ nghĩa.

- Dùng cách phiên âm (hay phiên chuyển nói chung). Các ví dụ: trong Tù điển Việt - Tày - Nùng (1984):

truyện tuyện. truyện đời xuaa: tuyện tởi ké.

việc việc, fiệc.

- Dùng cách phiên âm (hay phiên chuyển nói chung) kết hợp với cách tường giải bằng ngôn ngữ đích. Hoặc: vừa giải thích hay vừa phiên chuyển vừa ghi chú. Các ví dụ: Tù điển Việt - Êđê (2004):

Du kích I. Dêc, yu kic. Đánh du kích: Mblah dêc.

II. K'han buôn, yu kic. Gia nhập du kích:

Mut êpul k'han buôn.

hoặc trong Tù điển Việt - Tày - Nùng (1984):

anh hùng anh hùng (cần mỉ sluc rèng, tài tảm hêt pền công cải đuổi nuớc rươn).

chuột cống nu chú nặm (thình nu cải).

hoặc trong Tù điển Muoòng - Việt (2002):

cẳu cáu, lá cáu (một loại lá để ăn với trầu).

pàn lả mang cỗ được lót bằng lá chuối làm mâm (mâm dành cho kẻ hèn hạ hoạc trẻ con).

tả Chin Tang ông Chin Tang (một nhân vật trong mo Mưòng)...

Để các từ điển đối dịch Việt - DTTSvà DTTS- Việt có ích và tiện dùng nhất cho nhiều người đọc, nên theo hướng đa dạng hóa.

\section{Kết luận}

Trước hết, cần báo động về nguy cơ nói trên với các nhà hoạch định và thực hiện chính sách dân tộc, cũng như với những chủ nhân của các ngôn ngữ, về một tương lai ảm đạm: các dân tộc ở Việt Nam rốt cuộc giống nhau "như những giọt nước trên một dòng sông", 
sẽ nói bằng tiếng Việt hoặc một ngoại ngữ nào đó khác: tiếng mẹ đẻ chỉ còn trong kí ức.

Là loại công trình tra cứu cung cấp thông tin về nghĩa và cách sử dụng tương đương của các từ ngũ ngôn ngữ này với các từ ngữ ngôn ngữ khác, các TĐĐD có vai trò thiết thực đáng kể trong giáo dục, văn hóa truyền thông và sử dụng ngôn ngữ các dân tộc trong những hoàn cảnh đa dạng của đời sống; bảo tồn và phát triển ngôn ngữ của các dân tộc - đặc biệt của đồng bào các DTTS ở Việt Nam trong điều kiện hiện nay, cũng như tăng cường sự hiểu biết và quan hệ giữa các cộng đồng nói những ngôn ngữ, thuộc những nền văn hóa khác nhau....

Những cách giải quyết khó khăn ở trên cần áp dụng linh hoạt và có thể chưa đầy đủ. Trong Giáo trình tì điển hoc, L. Zgusta đã nhắc nếu trông chờ có những lời khuyên tỉ mỉ và cụ thể là điều trái lẽ thường, vì "mỗi ngôn ngữ còn có khá nhiều tính chất đặc thù của mình. Và không phải chỉ có thế, mỗi công trình từ điển học lại cũng có nhiều tính chất đặc thù của riêng nó, do mục đích, cơ sở văn hóa và truyền thống của nó quy định, do công chúng mà nó sẽ phục vụ, do khả năng cá nhân và sự ưa thích của tác giả" [19, tr 16].

\section{TÀI LIỆU THAM KHẢO}

1. Atkin B.T.Sue and Michel Rudell (2008), The Oxford Guide to Practical Lexicography, Oxford University Press.

2. Colin Baker, 2008, Nhũng co sở của giáo dục song ngũu và vấn đề song ngũ , Nxb Đại học quốc gia TP. Hồ Chí Minh, TP. Hồ Chí Minh.

3. Nguyễn Hữu Hoành (2010), Một số nhận xét buớc đầu về tù điển Việt - Dân tộc, Tr. "Từ điển học \& Bách khoa thư", s. 3(11).

4. Đặng Chấn Liêu (1997), Vài kinh nghiệm làm tù điển hai thư tiếng, "Ngôn ngữ", s. 3.

5. Vũ Lộc (2010), Nhũng vấn đề của tù điển hai thứ tiếng Nga - Việt, "Từ điển học \& Bách khoa thư", s. 5(7).

6. Hartmann R. R. K.and Gregory James (1998), Dictionary of Lexicography, Routledge London and New York.
7. Hoàng Tuệ...,1984, Ngôn ngũu các DTTSViệt Nam và chính sách ngôn ngũu, Nxb Khoa học xã hội, H.

8. Lê Khả Kế (1997), Một vài suy nghĩ về tù điển song ngũu, Tr. "Một số vấn đề Từ điển học", NXB Khoa học xã hội, $H$.

9. Kimmo Kosonen, 2004, Vai trò của ngôn ngũ trong hoc tập: nghiên cưu quốc tế nói về vấn đề này nhu thế nào? Tr. Kỉ yếu Hội nghị quốc gia: Chính sách, chiến lược sử dụng và dạy học tiếng dân tộc, tiếng Việt cho các DTTS, $H$.

10. Nguyễn Văn Lợi (2009), Dân tộc thiểu số, thông tin tri thức và tạp chi "Tù điển hoc \& Bách khoa thu", "Từ điển học \& Bách khoa thư", s. 1.

11. Nguyễn Văn Lợi (2012), Công trình tra cúu về ngôn ngũ và vấn đề bảo tồn ngôn ngũ có nguy co tiêu vong, "Từ điển học \& Bách khoa thư", s. 2(16).

12. Nguyễn Tuyết Minh (2010), Một số vấn đề li luận chung về tù điển hoc và tù điển song ngũu, Tr. "Một số vấn đề cơ bản về lí luận và phương pháp luận của thế giới và Việt Nam về biên soạn các loại từ điển" (đề tài cấp Bộ Viện Hàn lâm KHXH Việt Nam, 2009).

13, Nguyễn Tuyết Minh (2011), Tính đối chiếu của tì điển song ngũu, Tr. Kỉ yếu Hội thảo Ngữ học toàn quốc, Hội NNH VN- Trường ĐHNN, ĐH Đà Nẵng.

14 .Tạ Văn Thông,1993, Mối quan hệ giũa chũ và tiếng các DTTSvới chũ và tiếng Việt, Tr: Những vấn đề chính sách ngôn ngữ ở Việt Nam, NXB Khoa học xã hội, H.

15. Hồ Hải Thụy (2009), Tù̀ điển và Tù điển học ngày nay, "Từ điển học \& Bách khoa thư", s. 2.

16. Tổ chức Giáo dục, Khoa học và Văn hóa của Liên Hợp Quốc UNESCO Băng Cốc, 2007, Tài liệu huoóng dẫn Phát triển Chuoong trình Xóa mù chũ và Giáo dục cho ngườ lớn tại cộng đồng ngôn ngũ thiểu số, NXB Giao thông Vận tải, H.

17. Viện Ngôn ngữ học, 1993, Nhũng vấn đề chính sách ngôn ngũ ở Việt Nam, Nxb Khoa học xã hội, H.

18. Viện Ngôn ngữ học, 2002, Cảnh huống và chính sách ngôn ngũ ở Việt Nam, Nxb Khoa học xã hội, H.

19. Zgusta L. (1971), Giáo trình tì̀ điển học, Prague and the Hague (bản dịch của Viện Ngôn ngữ học). 


\section{Compiling translation dictionaries before Vietnamese languages sink in oblivion}

\section{Ta Van Thong}

\section{Article info}

Recieved:

20/7/2018

Accepted:

$10 / 12 / 2018$

Keywords:

Dictionaries; vocabulary; ethnic minority language; languages at risk of sinking in oblivion

\begin{abstract}
Many ethnic minorities in Vietnam are currently facing the risk that their language and cultural forms stored and developed in their native language are sunk in oblivion. Compiling dictionaries is considered as one of the measures to help the above languages escape from the risk.

Translation dictionaries shall be construed as a dictionary that explains word units (entries) of a language by using a second language, which means translating one thing to another.

This article serves the purpose of: identifying requirements set forth and directions for solving compilation of Vietnamese- ethnic minority language dictionaries and ethnic minority language- Vietnamese dictionaries from the theory and reality of compiling translation dictionaries (TDDD, also known as "reference dictionary"; or "two-language dictionary", "bilingual dictionary" - base in the common form of this dictionary).

That is: types of translation dictionaries needed in Vietnam; writing; dialect selection; setting up a list of entries: volume, types of language units, sources of word collection. In addition: how to translate in the dictionary.
\end{abstract}

